\title{
Phenolic acid content and in vitro antioxidant capacity of einkorn water biscuits as affected by baking time
}

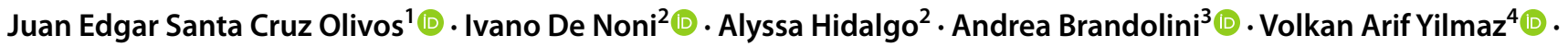 \\ Stefano Cattaneo ${ }^{2}$ (1) Enzio M. Ragg ${ }^{2} \mathbb{D}$
}

Received: 11 August 2020 / Revised: 7 November 2020 / Accepted: 14 November 2020 / Published online: 8 December 2020

(c) The Author(s) 2020

\begin{abstract}
Aim of this research was to study the evolution of heat damage, phenolic acid content and in vitro antioxidant capacity of whole meal einkorn water biscuits baked at $205{ }^{\circ} \mathrm{C}$ for increasing times ( $10 \mathrm{~min}$ steps) from 25 to $75 \mathrm{~min}$. The heat damage was gauged by determining furosine, hydroxymethylfurfural (HMF), furfural and glucosylisomaltol (GLI) contents. Furosine increased up to $50 \mathrm{~min}$ baking, when HMF started to form; furfural augmented only after 65 min treatment, whereas GLI did not change. An unknown compound, apparently related to the severity of the heat load, aroses through the aldolic condensation of HMF with the acetone used for the extraction of phenolic acids; hence the use of acetone-based solvents in thermally processed cereal products should be avoided. The conjugated phenolic acids ferulic, vanillic, syringic, $p$-coumaric, $p$-hydroxybenzoic and syringaldehyde and the bound phenolic acids ferulic, $p$-coumaric, syringic, and $p$-hydroxybenzoic were identified in water biscuits. The stronger heating treatments led to an increase of the soluble conjugated compounds, but did not influence the bound fraction. The in vitro antioxidant capacity of water biscuits augmented significantly as baking time increased, likely for the formation of antioxidant compounds as a consequence of heat damage.
\end{abstract}

Keywords ABTS $\cdot$ FRAP $\cdot$ Heat damage $\cdot$ Insoluble-bound phenolics $\cdot$ Soluble conjugated phenolics $\cdot$ Triticum monococcum

\section{Introduction}

Phenols are secondary metabolites synthesized by plants in response to pests, diseases and stresses. They are excellent oxygen radical scavengers, and as such can exert a beneficial impact on human health; in particular, they show

Alyssa Hidalgo

alyssa.hidalgovidal@unimi.it

1 Departamento de Tecnología de Alimentos y Productos Agropecuarios, Facultad de Industrias Alimentarias, Universidad Nacional Agraria la Molina (UNALM), Av. La Molina s/n, Lima 12, Peru

2 Department of Food, Environmental and Nutritional Sciences (DeFENS), University of Milan (UNIMI), Via Celoria 2, 20133 Milan, Italy

3 Unità di Ricerca per la Zootecnia e l'Acqualcoltura, Consiglio per la Ricerca in Agricoltura e l'analisi dell'Economia Agraria (CREA), Via Piacenza 29, 26900 Lodi (LO), Italy

4 Department of Food Engineering, Faculty of Engineering, Ondokuz Mayis University, Kurupelit 55139 Samsun, Turkey anti-inflammatory, anti-microbial, anti-thrombotic, anti-atherogenic, vasodilatatory and cardio-protective effects [1]. Phenolic acids, the main phenols present in wheat kernels [2], are often scarce in commercial wheat flours, because they are mainly present in the aleuronic and hyaline layers, in the germ and in the seed coat [3,4], which are usually eliminated during milling. Phenolic acids are present as soluble free, soluble conjugated and insoluble-bound [5]. The free soluble fraction represents about $1 \%$ of total phenols. The soluble conjugated phenolic acids, esterified to sugars and other low molecular weight components, and the insolublebound phenolic acids, linked to cell wall constituents, represent about $22 \%$ and $77 \%$ of the total phenols [2]. However, the free soluble phenols easily cross the human intestinal barrier, whereas bound and conjugated forms are not readily absorbable. A partial conversion from bound to conjugated during in vitro intestinal digestion has been observed [6]; additionally, bound phenolic acids can be partly degraded in the colon by bacterial enzymes [7, 8]. Although the bioavailability of phenolic compounds hydrolyzed by colon microbiota is lower than those of the free phenols readily 
absorbed in the small intestine [9], their abundance makes them a likely target to improve phenols nutritional availability. Therefore, several authors have studied the factors that trigger the passage from bound to conjugated phenolics during processing, such as maturation stage and fermentation [10], germination [11, 12], extrusion [13], baking [14], puffing [15], etc.

Some studies have investigated the changes in bioactive compounds and antioxidant capacity induced by baking, focusing mainly on heat damage and Maillard reaction products. Temperature, baking time and development of Maillard reactions can trigger the release of bound molecules as well as the loss of nutritional properties, along with an increase of Maillard reaction products and antioxidant capacity [16].

The reliable determination of phenolic acids is often a challenge, because the complex matrix and properties of foods hinder their retrieval. The free forms can be extracted using organic solvents, but the conjugated and bound forms require acid or base hydrolysis to free them from the cell wall matrix. Many solvents have been used to extract phenolic acids: ethanol-water [17], acidified methanol-water [18], isopropanol, acetonitrile, acetone-water [19], ethanol-acetic acid [20], methanol-acetone-water [21], etc.; in particular, this last mixture has been broadly adopted because of its effectiveness [4, 22, 23].

Einkorn (Triticum monococcum L. subsp. monococcum) is a diploid hulled wheat, allied to durum and bread wheat. The renewed interest for this cereal is linked to its high protein, carotenoid and tocol contents [15], as well as to its thrifty nature and disease resistance that favour low-input or organic management and propose it as an environmentfriendly crop [24].

Aim of our research was to study the changes in phenolic composition and content, antioxidant capacity and heat damage of einkorn water biscuits (WB) during the baking process carried out for different times.

\section{Materials and methods}

\section{Materials}

Monlis, the most widespread Italian einkorn cultivar, was cropped in 2018-2019 at Sant'Angelo Lodigiano (45 $13^{\circ} 40^{\prime \prime}$ $\mathrm{N} 9^{\circ} 25^{\prime} 21^{\prime \prime} \mathrm{E}$, Po plain, Italy) in $10 \mathrm{~m}^{2}$ plots arranged in a randomised complete block design with three replications, following standard cultural practices. After harvesting, the kernels from the three replications were combined and stored at $5{ }^{\circ} \mathrm{C}$. Before processing, the seeds were de-hulled with an Otake FC4S thresher (Satake, Japan). Whole meal flour for biscuit preparation was obtained from kernels ground with a Cyclotec 1093 lab mill (FOSS Tecator, Denmark).

\section{Water biscuits preparation}

The WB were manufactured using only whole meal flour (30 g dry weight basis for each WB) and water, to unambiguously determine the role of flour in phenolic acid changes. Optimum water quantity and mixing time of each sample were determined by Brabender farinograph analysis. Dough mixing was carried out with a cookie dough micromixer (National Mfg. Co, Lincoln, Nebraska, USA). The dough was transferred to ungreased cookie sheets covered with parchment paper, rolled to $7 \mathrm{~mm}$ thickness using gauge strips and a rolling pin, and cut with a cookie cutter (inside diameter: $60 \mathrm{~mm}$ ). Baking was carried out at $205{ }^{\circ} \mathrm{C}$ for increasing times ( 10 min steps) from 25 to $75 \mathrm{~min}$, to study the changes under different heat conditions; acceptable water biscuits are obtained after 25 and $35 \mathrm{~min}$, while after $55 \mathrm{~min}$ they become hard and after 75 min scorched. Four WB were prepared for each accession. Baked WB were collected, stored at $-20{ }^{\circ} \mathrm{C}$ until analysis, and finely ground with a commercial heavy-duty blender (Waring, Torrington, USA) just before analysis.

\section{Chemical analysis}

Dry matter (DM) content was determined following method 44-15 [25]. Water activity $\left(a_{w}\right)$ was evaluated using the Aqua Lab model Series 3 TE instrument (Decagon Devices, Inc, Pullman, WA, USA). Levels of furosine, glucosylisomaltol (GLI), hydroxymethylfurfural (HMF) and furfural in WB were determined by HPLC as reported by Hidalgo and Brandolini [26]. Soluble conjugated and insoluble-bound phenolic acids were analysed by RPHPLC as described by Brandolini et al. [4]. The phenolic extracts were prepared as outlined in Moore et al. [23], with little modifications. Exactly $0.5 \mathrm{~g}$ of sample were mixed with $15 \mathrm{~mL}$ of a methanol/acetone/water (7:7:6) solution. After $15 \mathrm{~min}$ in an ice bath under discontinuous vortexing and after centrifugation $(11,200 \mathrm{~g}, 10 \mathrm{~min}$, $8{ }^{\circ} \mathrm{C}$ ) with a Centrikon K24 centrifuge (Kontron Instruments, Bletchley, UK), the supernatant was recovered; the extraction from the sediment was repeated twice more, the three extracts were pooled and evaporated under vacuum at $35{ }^{\circ} \mathrm{C}$ for $18 \mathrm{~min}$ with a rotator evaporator Laborota 4000 (Heidolph, Milan, Italy). To recover the soluble conjugated and the insoluble-bound phenolic compounds, the pooled supernatants and the sediments were separately hydrolysed with $15 \mathrm{~mL}$ of $4 \mathrm{M} \mathrm{NaOH}$ under nitrogen for $4 \mathrm{~h}$ at room temperature and continuous shaking. The samples were then brought to $\mathrm{pH} 1.5-2.0$ with $6 \mathrm{M}$ HCL and extracted twice with $20 \mathrm{~mL}$ of ethyl ether/ethyl acetate $(1: 1 \mathrm{v} / \mathrm{v})$. The extracts were clarified with anhydrous sodium sulphate, 
filtered with glass fibre $110 \mathrm{~mm}$ (Whatman, Maidstone, England), evaporated as previously outlined, suspended in $2 \mathrm{~mL}$ of methanol:water $(1: 1 \mathrm{v} / \mathrm{v})$ and filtered with a $0.22 \mathrm{~mm}$ PTFE membrane (Millipore, Carrigtwohill Co, Cork, Ireland) for HPLC injection. All the analyses were performed twice.

\section{Structural characterization of unknown chromatographic peak}

The chromatographic peak eluting at 20.0 min during the RP-HPLC pattern of soluble conjugated phenolic acids was collected from ten runs and dried under vacuum at $20^{\circ} \mathrm{C}$. After dilution with water, the collected fraction was submitted to RP-HPLC/HR-MS using the same chromatographic conditions [4] and by coupling the HPLC separation module to a Q Exactive hybrid quadrupole-Orbitrap mass spectrometer through an HESI-II probe for electrospray ionisation (Thermo Scientific, San Jose, CA, USA). The ion source and interface conditions were: spray voltage $+3.0 \mathrm{kV}$, sheath gas flow 60 arbitrary units, auxiliary gas flow 20 arbitrary units and temperature $300{ }^{\circ} \mathrm{C}$, capillary temperature $350{ }^{\circ} \mathrm{C}$. Positive mass calibration was performed with Pierce LTQ ESI Positive Ion Calibration Solution (Thermo Scientific Pierce, Rockford, IL, USA). The RP-HPLC eluate was analyzed by Full MS and tandem MS analysis $\left(\mathrm{MS}^{2}\right)$. The resolution was set at 70,000 and 17,500 and the AGC targets were $1 \times 10^{6}$ and $1 \times 10^{5}$ for Full MS and $\mathrm{MS}^{2}$ scan types, respectively. The maximum ion injection times were $50 \mathrm{~ms}$. The MS data were processed using Xcalibur software (Thermo Scientific, San Jose, CA, USA).

The vacuum-dried fraction was also submitted to nuclear magnetic resonance (NMR) spectroscopy. To this purpose, the vacuum-dried fraction was dissolved in $0.6 \mathrm{~mL}$ methanol- $\mathrm{d}_{4}$ or acetone- $\mathrm{d}_{6}$ (Sigma-Aldrich, Milan, Italy) and immediately transferred to a $5 \mathrm{~mm}$ NMR tube (Wilmad 535-PP). ${ }^{1} \mathrm{H}-\mathrm{NMR}$ spectra were recorded at $25^{\circ} \mathrm{C}$ on a Bruker AV600 spectrometer (Bruker Spectrospin AG, Rheinstetten, Germany), operating at $600.10 \mathrm{MHz}$ for the ${ }^{1} \mathrm{H}$ nucleus and equipped with a standard triple-resonance probe with $\mathrm{z}$-axis gradients and temperature control unit. ${ }^{1} \mathrm{H}$-chemical shifts were measured in $\delta(\mathrm{ppm})$, using as reference the acetone- $\mathrm{d}_{5}$ residual peak, set at $\delta 2.096$ [27]. All 2D spectra were obtained in phase-sensitive mode using standard pulse sequences. 2D-NOESY experiments were performed using $0.6 \mathrm{~s}$ mixing time, while the spin-lock duration for the 2D-TOCSY experiment was set at $80 \mathrm{~ms}$. Other relevant acquisition parameters for all experiments: time domain: $4 \mathrm{~K}$; number of scans: 16-48; relaxation delay for 2D-TOCSY: $2.5 \mathrm{~s}$ and for 2D-NOESY: $3 \mathrm{~s}$. Raw data were Fourier-transformed after apodization with a $90^{\circ}$-shifted sine-bell-squared function, zero-filling to $2 \mathrm{~K} \times 2 \mathrm{~K}$ real data points and baseline corrected. Spectra were processed using
Bruker software TOPSPIN v.1.3. Spectral data are reported for the compound dissolved in acetone- $\mathrm{d}_{6}$.

\section{Antioxidant capacity}

The samples were extracted as in Yilmaz et al. [28]. Briefly, exactly $0.5 \mathrm{~g}$ sample were weighed and extracted with $5 \mathrm{~mL}$ of methanol:water (80:20 v:v) acidified with $1 \% \mathrm{HCl}(\mathrm{MeOH}: \mathrm{HCl})$ under agitation using Vortex $(30 \mathrm{~s})$ and a multi-rotator stirrer PTR-35 (Grant-bio, England) for $30 \mathrm{~min}$ at $4{ }^{\circ} \mathrm{C}$ in the dark. The mixtures were centrifuged at $11,200 \mathrm{~g}$ for $10 \mathrm{~min}$ at $8{ }^{\circ} \mathrm{C}$ and the supernatants recovered; after re-extracting the residues, the supernatants were pooled, giving $10 \mathrm{~mL}$ crude extracts.

The saturated butanol $(\mathrm{BuOH})$ extracts were obtained performing a single extraction with $0.5 \mathrm{~g}$ of sample and $10 \mathrm{~mL}$ of solvent under agitation with Vortex $(30 \mathrm{~s})$ and orbital stirrer $(2 \mathrm{~h})$ at $4{ }^{\circ} \mathrm{C}$ in the dark followed by centrifugation as formerly described.

The ABTS [2,2'-azino-bis(3-ethylbenzothiazoline-6-sulphonic acid)] radical cation scavenging capacity was analysed as described by Re et al. [29], with the minor changes reported by Yilmaz et al. [28]. The FRAP (reduction of the Fe(III)e2,4,6-tripyridyl-s-triazine complex to the ferrous form at low $\mathrm{pH}$ ) test was determined following Benzie and Strain [30], with the small modifications described by Yilmaz et al. [28]. The antioxidant capacity was expressed as $\mathrm{mmol} \mathrm{TE} / \mathrm{kg} \mathrm{DM}$.

\section{Results and discussion}

To better understand the relationships among content of soluble conjugated and insoluble-bound phenolic acids, antioxidant capacity and heat damage, their evolution was studied during baking of WB prepared from Monlis whole meal flour (Fig. 1a-d, respectively). Furosine increased up to $45 \mathrm{~min}$ and then steeply declined, HMF started growing after $45 \mathrm{~min}$, in correspondence to furosine decrease, while GLI and furfural somewhat augmented only after long baking times. The evolution of these heat-damage markers was similar to that reported by Hidalgo and Brandolini [26] during baking of WB made from refined bread wheat flour; nonetheless, the levels of GLI, furosine, HMF and furfural were generally higher (Fig. 1d) in the einkorn WB studied in the present work. Ait Ameur et al. [31] studied the kinetics of HMF in the advanced stages of baking and observed that HMF was very sensitive to $a_{w}$, reporting that a low $a_{w}(0.51)$ at baking temperatures of $200-250{ }^{\circ} \mathrm{C}$ was critical for HMF formation. The $a_{w}$ in the whole meal flour WB was 0.80 after $25 \mathrm{~min}$ and decreased to 0.48 at $35 \mathrm{~min}$, while the $a_{w}$ in the white flour WB remained stable at 0.8 up to $55 \mathrm{~min}$ [26]. 
Fig. 1 Evolution of soluble conjugated phenolic acids (a), insoluble-bound phenolic acids (b), ABTS and FRAP antioxidant capacity of saturated butanol $(\mathrm{BuOH})$ and/or methanol acidified with hydrochloric acid (MeOH:HCl) extracts (c), and glucosylisomaltol (GLI), hydroxymethylfurfural (HMF), furfural, furosine (d) during baking at different times of Monlis water biscuits. The dotted lines refer to the unknown compounds with peaks at 12 and 20 min retention times; the values correspond to area/100,000. The error bars represent the standard error
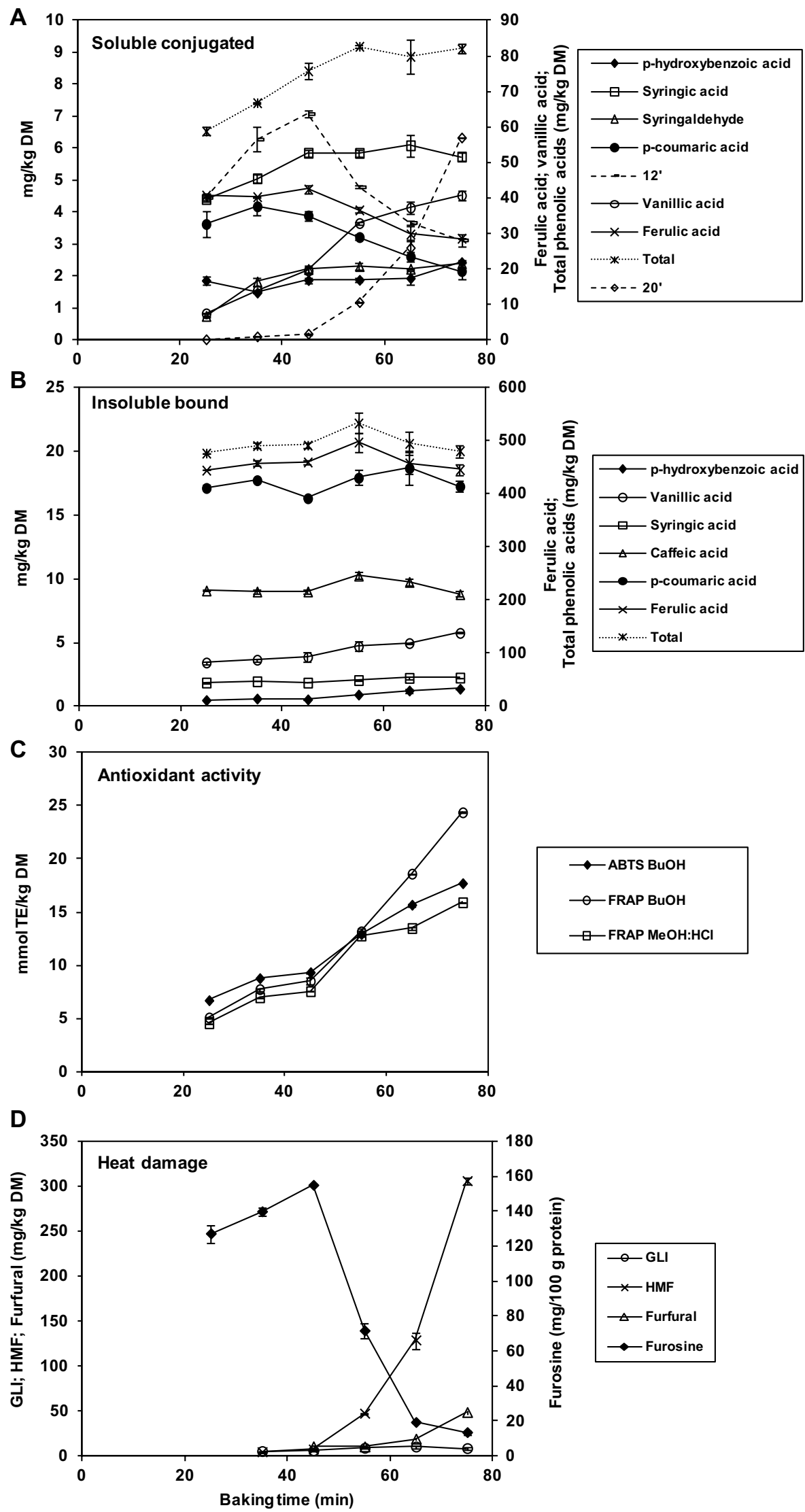


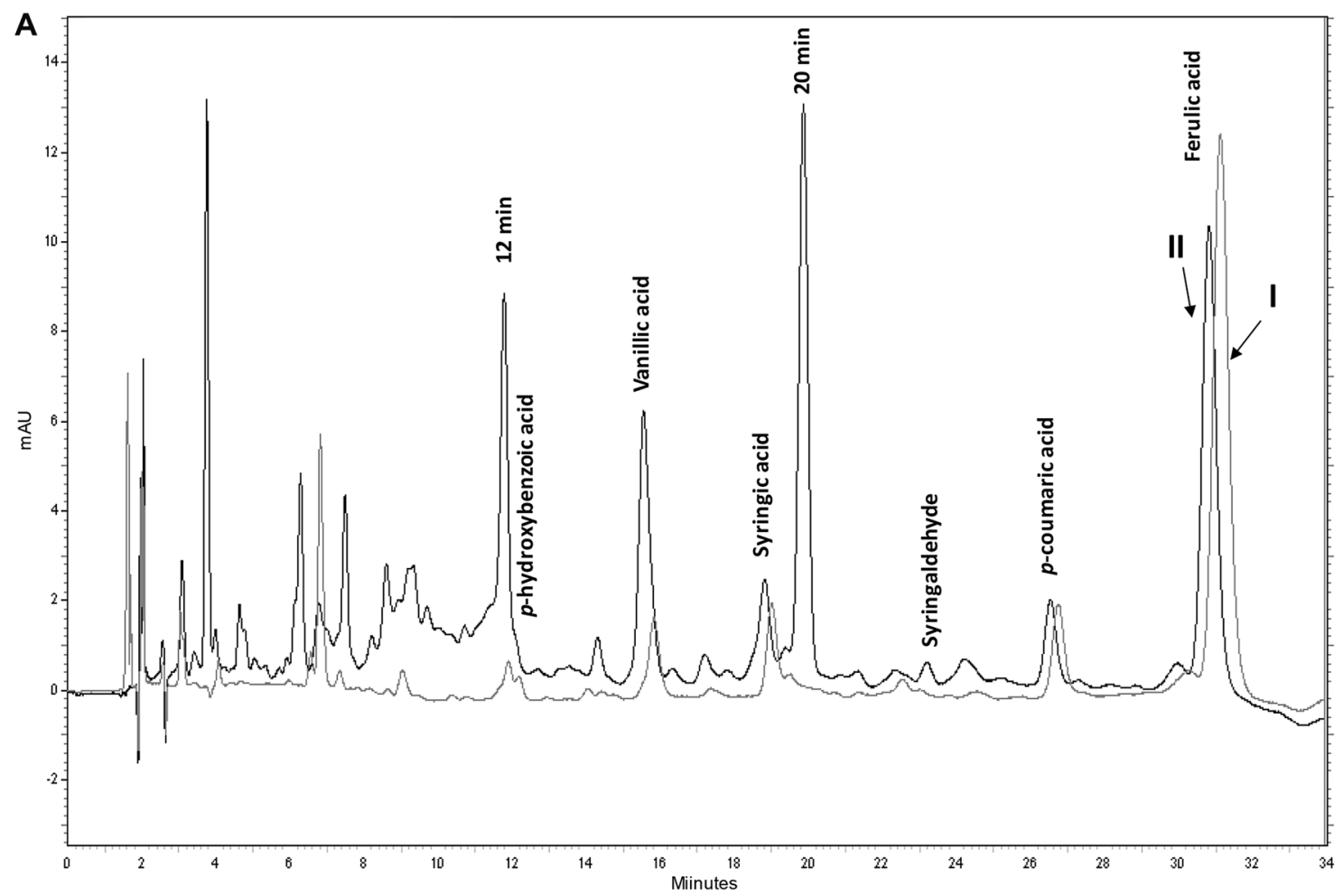

B

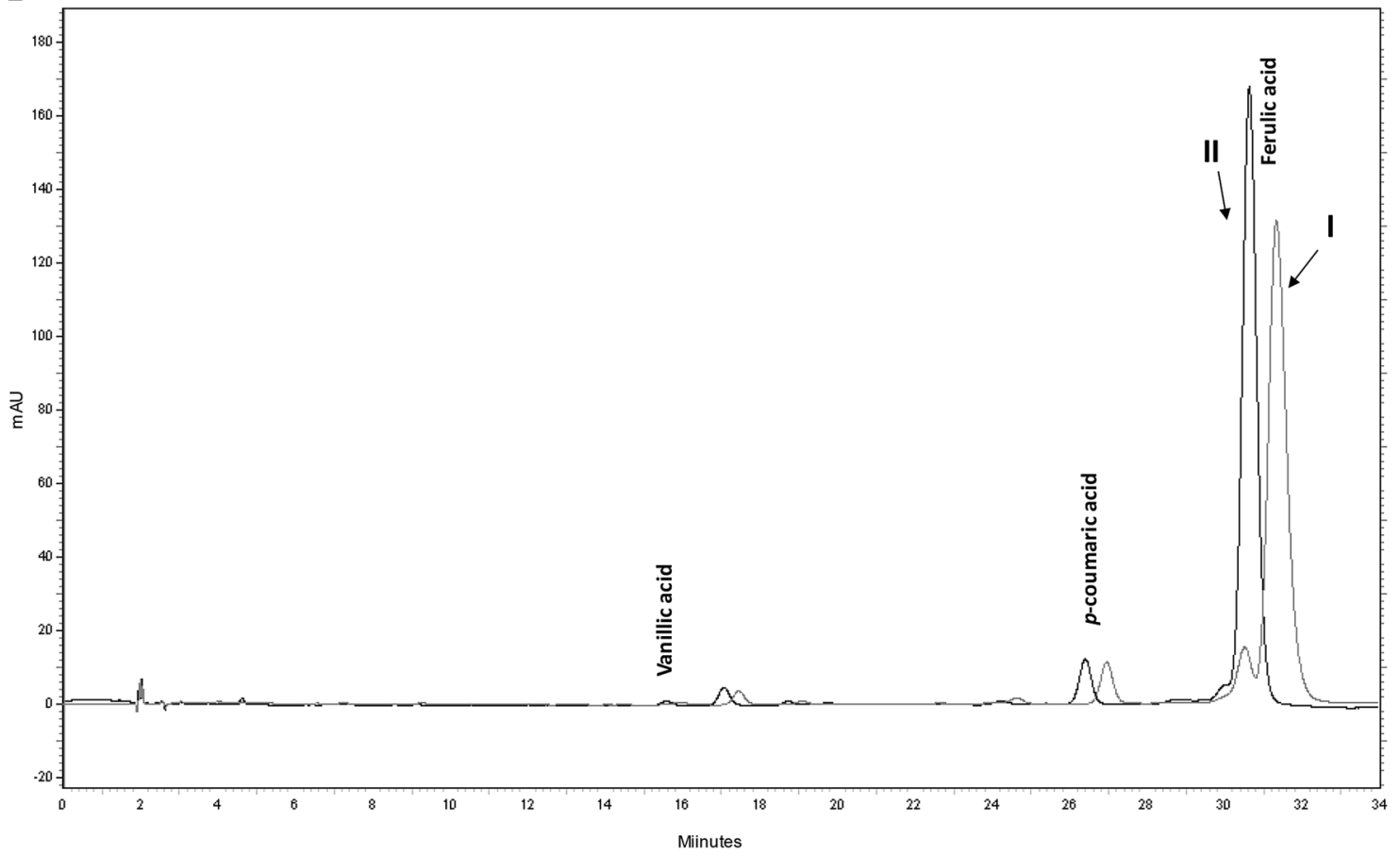

Fig. 2 Chromatogram of the soluble conjugated (a) and insoluble-bound (b) phenolic acids extracted with methanol/acetone/water from Monlis whole meal flour (I) and from water biscuits baked for $55 \mathrm{~min}$ (II)

Two major unknown peaks appeared at 12 and $20 \mathrm{~min}$ retention times in the RP-HPLC pattern of the soluble conjugated extracts (Fig. 2a). The former compound increased until $45 \mathrm{~min}$ and then rapidly diminished, while the latter compound continued growing (Fig. 1a). Their evolution mirrored those of furosine and HMF, respectively (Fig. 1d). Therefore, the importance of the compound eluting at $12 \mathrm{~min}$ and its possible contribution to the antioxidant capacity are 
probably limited to foods from low heat-stress treatments. On the other hand, the compound eluting at 20 min may be a major player in determining the antioxidant properties of bakery products under severe heat-stress conditions. Its spectrum differed from that of HMF (maximum absorbance wavelength at $327 \mathrm{~nm}$ instead of $284 \mathrm{~nm}$, respectively). To identify this compound, the eluting fraction corresponding to the unknown peak was collected from RP-HPLC and was analysed by RP-HPLC/HR-MS. Surprisingly, the resulting chromatographic pattern showed a peak eluting at $22.5 \mathrm{~min}$ in addition to the expected one eluting at $20.0 \mathrm{~min}$ (not shown). Both peaks had the same UV spectrum (maximum absorbance at $327 \mathrm{~nm}$ ) and the same accurate mass $\left(\mathrm{MH}^{+}:\right.$167.0630), corresponding to a $\mathrm{C}_{9} \mathrm{H}_{10} \mathrm{O}_{3}$ molecular formula (calculated: $166.06298 \mathrm{Da}$ ). The MS ${ }^{1}$ spectra of the two chromatographic peaks overlapped completely and three major fragments $\left(\mathrm{MH}^{+}: 149.0598,121.0651,93.0706\right)$ were recorded.

The ${ }^{1} \mathrm{H}-\mathrm{NMR}$ spectrum $(600 \mathrm{MHz}$, acetone-d6; Fig. 3a) confirmed the presence of two molecules at an approximately 75:25 molar ratio. The ${ }^{1} \mathrm{H}-\mathrm{NMR}$ spectrum of the major component (75\%) exhibited two trans-olefinic protons at $\delta 7.40$ and $6.55\left({ }^{3} \mathrm{~J}_{\mathrm{H}, \mathrm{H}}=16.0 \mathrm{~Hz}\right)$, two aromatic signals at $\delta 6.84$ and $6.48\left({ }^{3} \mathrm{~J}_{\mathrm{H}, \mathrm{H}}=3.4 \mathrm{~Hz}\right)$, one oxygenated methylene group as a singlet at $\delta 4.62$, and one methyl singlet at $\delta 2.32$. The ${ }^{1} \mathrm{H}-\mathrm{NMR}$ spectrum of the minor component (25\%) exhibited two cis-olefinic protons at $\delta 6.67$ and 6.22 $\left({ }^{3} \mathrm{~J}_{\mathrm{H}, \mathrm{H}}=13.4 \mathrm{~Hz}\right)$, two aromatic signals at $\delta 7.81$ and 6.46 $\left({ }^{3} \mathrm{~J}_{\mathrm{H}, \mathrm{H}}=3.4 \mathrm{~Hz}\right)$, one oxygenated methylene group as a singlet at $\delta 4.59$, and one methyl singlet at $\delta 2.29$. The small value of the vicinal coupling constant between the aromatic protons suggested a furyl moiety. For both components, the
Fig. 3 a ${ }^{1} \mathrm{H}$ 2D-NMR TOCSY spectrum of the 20.0/22.5 min. HPLC peaks (acetone- $\mathrm{d}_{6}$, $600 \mathrm{MHz}$, spin-lock: $80 \mathrm{~ms}$, $25^{\circ} \mathrm{C}$ ). The intra-residue interactions for isomer 1 are made evident with boxes. The 1D-NMR spectrum is shown on top; (b) trace of a 2D-NOESY spectrum $\left(t_{\text {mix }}=0.6 \mathrm{~s}, 25^{\circ} \mathrm{C}\right)$ extracted at $\delta 2.32$, showing the through-space interactions between 1- $\mathrm{CH}_{3}$ and 4-H,3-H protons of isomer 1. Structures and numbering of isomers 1 and 2 are shown at bottom. The observed NOESY and TOCSY interactions are depicted as single and double arrows, respectively
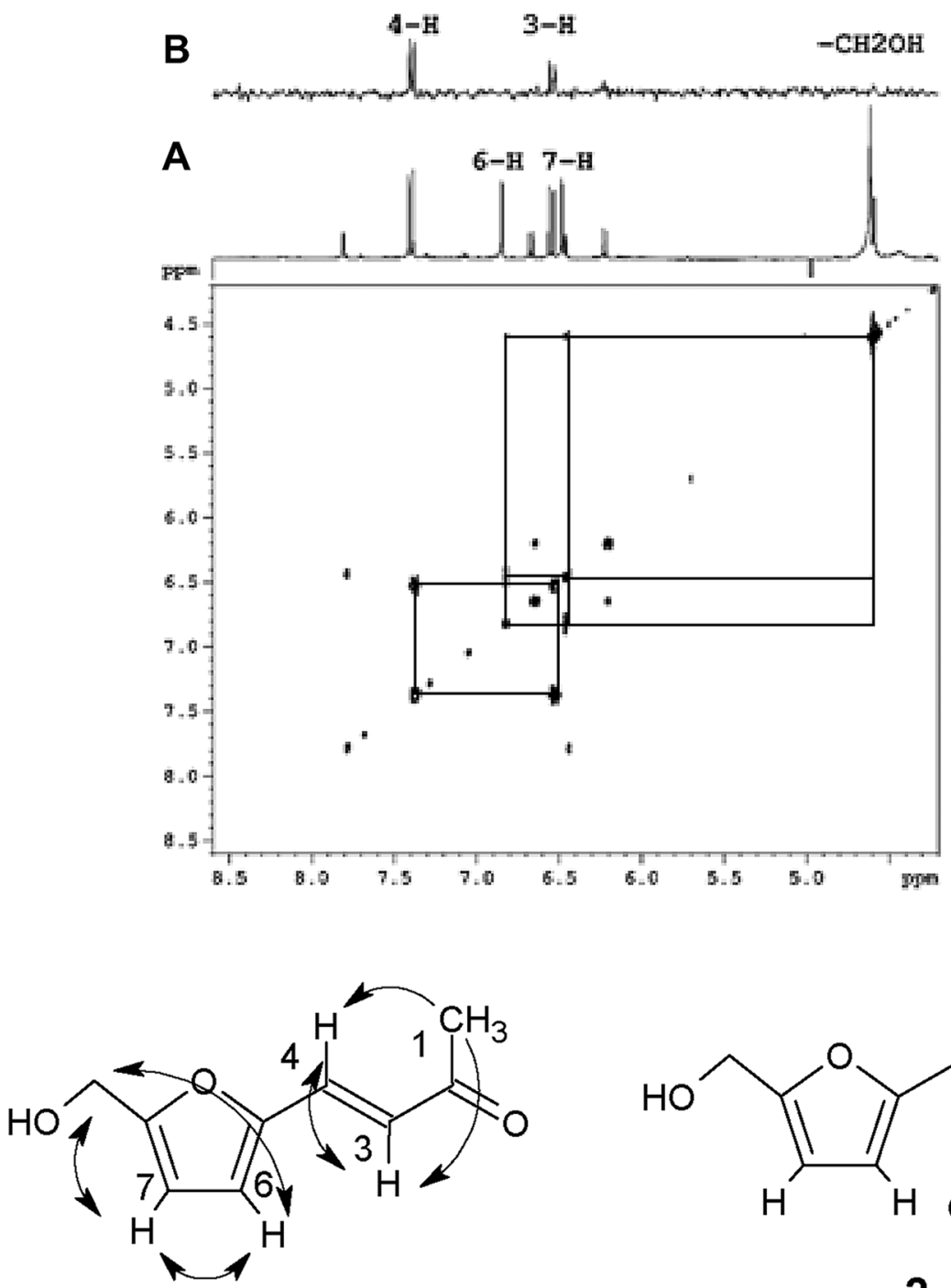<smiles>CC(=O)/C=C/c1ccc(CO)o1</smiles>

2 $(25 \%)$

$1(75 \%)$ 
${ }^{1} \mathrm{H}$ connectivity and spatial proximity were established by analysis of 2D-TOCSY/COSY and 2D-NOESY experiments, respectively. The hydroxymethylene group $\left(\mathrm{CH}_{2} \mathrm{OH}\right)$ showed a long-range connectivity with 6- $\mathrm{H}$ and $7-\mathrm{H}$ of the furyl moiety (Fig. 3a), while the methyl group was detected by means of the NOESY interaction observed for the olefinic protons (Fig. 3b). Chemical shifts and coupling constants were consistent with published data for 4-[5-(hydroxymethyl)2-furyl]-3(E)-buten-2-one [32]. Some minor discrepancies might be explained by the different solvents used for the NMR experiments (acetone- $\mathrm{d}_{6}$ vs. chloroform-d). Finally, the UV maximum absorbance, with a measured $43 \mathrm{~nm}$ bathochromic effect compared to HMF $\left(\lambda_{\max }=283 \mathrm{~nm}\right)$, confirmed the presence of an $\alpha, \beta$-unsatured ketone-conjugated furane chromophore. Hence, on the basis of RP-HPLC/ HR-MS and NMR data, the chromatographic peak eluting at 20.0 min should be assigned to 4-[5-(hydroxymethyl)-2furanyl]-3(E)-buten-2-one (Fig. 3, compound 1). The additional peak at $22.5 \mathrm{~min}$ was the less thermodynamically stable isomer 4-[5-(hydroxymethyl)-2-furanyl]-3(Z)-buten2-one (Fig. 3, compound 2), likely to result from the isomerisation of 3-buten-2-one,4-[5-(hydroxymethyl)-2-furanyl](3E) during vacuum drying. These two molecules originate from the aldol condensation and subsequent dehydration of HMF with acetone during the extraction of phenolic compounds. Such a reaction has been thoroughly studied in the production of fuels from biomass-derived carbohydrates [33] and there is a general agreement about the positive role of metal oxides as Lewis acids in the aldol condensation catalysis [34]. As whole meal flours are generally rich in divalent ions [35], given the basic conditions used during the extraction process (see "Materials and methods"), it is feasible to assume that the WB prepared from whole meal flour provide the right catalytic conditions to promote an aqueousphase aldolic condensation of HMF with the acetone used as an extraction solvent (see scheme in Fig. 4) [36].

The two isomers represent, therefore, chemical artefacts, which must be considered when using acetone for assessing the phenolic acid composition of baked products. A clear-cut evidence that compounds 1 and 2 derive from HMF during the extraction is reported in Fig. 5, which compares the HPLC analysis of extracts performed with and without acetone (traces A and B, respectively). It is evident that compound 1 was detected only in the acetone extract, at a concentration inversely proportional to that of HMF.
Fig. 4 Proposed mechanism of base-catalysed aldol condensation between HMF and acetone. Isomers 1 and 2 readily interconvert during workup through double bond isomerisation<smiles>C=C(C)CCCCC(=O)c1ccc(CO)o1</smiles><smiles>CC(=O)C(C)C([O-])C(CC(C)O)c1ccc(CO)o1</smiles><smiles>CC(=O)/C=C\c1ccc(CO)o1</smiles>

$\underline{2}(25 \%)$<smiles>CC(=O)/C=C/c1ccc(CO)o1</smiles>

$1(75 \%)$ 


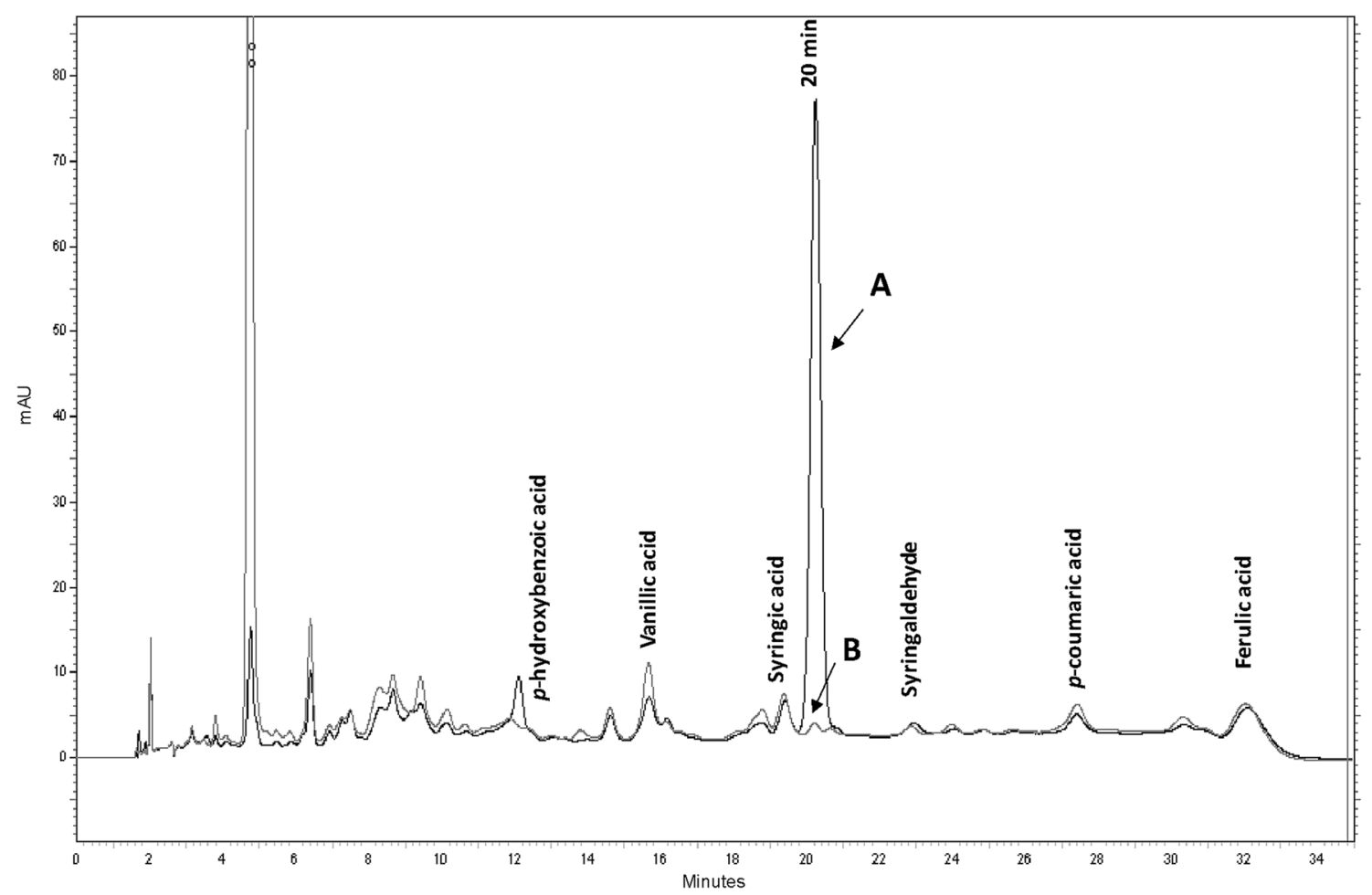

Fig. 5 Chromatogram of the soluble conjugated phenolic acids extracted with (a; methanol/acetone/water) and without (b; methanol/water) acetone from water biscuits baked for $75 \mathrm{~min}$

The conjugated phenolic acids (Fig. 2a) identified in the WB were ferulic, vanillic, syringic, $p$-coumaric, $p$-hydroxybenzoic and syringaldehyde, while the bound phenolic acids (Fig. 2b) were ferulic (by far the most abundant), $p$-coumaric, syringic, and $p$-hydroxybenzoic acids. These phenols (plus caffeic acid at low concentration) were also observed in similar products [15]. In the soluble phenolic extracts, ferulic and $p$-coumaric acid initially increased, but then decreased significantly after $45 \mathrm{~min}$, while $p$-hydroxybenzoic acid, syringic acid and syringaldehyde increased slightly and vanillic acid kept growing steadily throughout all the baking time; the insoluble-bound fraction composition, instead, generally did not change, although vanillic acid steadily increased during baking. These results are in line with those reported by Hidalgo et al. [15] for WB baked for 25 and $35 \mathrm{~min}$. The same authors noticed that stronger heating treatments, such as those applied during kernels puffing, led to higher increases of the soluble conjugated compounds, but still did not influence the bound fraction. The authors suggested that the increase in soluble conjugated phenolic acids might be related to heat-induced rupture of certain ester bonds, and thus to an increase in extractable compounds.

The insoluble-bound phenolic acids syringic, caffeic, $p$-coumaric and ferulic did not show significant variations during baking, whereas the $p$-hydroxybenzoic and vanillic acids increased slightly from 45 min onwards. Hence, the increase of some phenolic acids in the soluble conjugated fraction does not seem to be related to a partial degradation of insoluble-bound phenolics.

The in vitro antioxidant capacity of saturated butanol and acidified methanol-water extracts augmented significantly as the baking time passed from 25 to 75 min (Fig. 1c). This increase does not seem justified by the changes in concentration of phenolic acids or of other antioxidant molecules such as carotenoids and tocols, whose levels diminish during processing [37, 38]. Therefore, the most likely explanation is the formation of antioxidant compounds during baking as a consequence of the Maillard reaction, as suggested for bread crust [39, 40] and for biscuits [41, 42].

\section{Conclusions}

This research demonstrates the high stability of soluble conjugated and insoluble-bound phenolic acids even after long baking times. The increased antioxidant capacity after baking is more a consequence of heat damage than of conjugated and bound phenols liberation. The use of acetone during extraction should be considered with caution or even avoided, as it might lead to artefacts arising from undesired aldol condensation products with furan 
aldehydes. Nevertheless, the effectiveness of other solvents for extracting free phenols from water biscuits and, in general, thermally processed cereal products needs further experimental evidence.

Funding Open access funding provided by Università degli Studi di Milano within the CRUI-CARE Agreement.

\section{Compliance with ethical standards}

Conflict of interest The authors declare that they have no conflict of interest.

Ethical approval This article does not contain any studies with human or animal subjects.

Open Access This article is licensed under a Creative Commons Attribution 4.0 International License, which permits use, sharing, adaptation, distribution and reproduction in any medium or format, as long as you give appropriate credit to the original author(s) and the source, provide a link to the Creative Commons licence, and indicate if changes were made. The images or other third party material in this article are included in the article's Creative Commons licence, unless indicated otherwise in a credit line to the material. If material is not included in the article's Creative Commons licence and your intended use is not permitted by statutory regulation or exceeds the permitted use, you will need to obtain permission directly from the copyright holder. To view a copy of this licence, visit http://creativecommons.org/licenses/by/4.0/.

\section{References}

1. Quiñones M, Miguel M, Aleixandre A (2013) Beneficial effects of polyphenols on cardiovascular disease. Pharmacol Res 68:125-131

2. Li L, Shewry PR, Ward JL (2008) Phenolic acids in wheat varieties in the Healthgrain diversity screen. J Agric Food Chem 56:9732-9739

3. Barron C, Surget A, Rouau X (2007) Relative amounts of tissues in mature wheat (Triticum aestivum L.) grain and their carbohydrate and phenolic acid composition. J Cereal Sci 45:88-96

4. Brandolini A, Castoldi P, Plizzari L, Hidalgo A (2013) Phenolic acids composition, total polyphenols content and antioxidant activity of Triticum monococcum, Triticum turgidum and Triticum aestivum: a two-years evaluation. J Cereal Sci 58:123-131

5. Naczk M, Shahidi F (2004) Extraction and analysis of phenolics in food. J Chromatogr A 1054:95-111

6. Hidalgo A, Ferraretto A, De Noni I, Bottani M, Cattaneo S, Galli S, Brandolini A (2018) Bioactive compounds and antioxidant properties of pseudocereals-enriched water biscuits and their in vitro digestates. Food Chem 240:799-807

7. Guo W, Beta T (2013) Phenolic acid composition and antioxidant potential of insoluble and soluble dietary fibre extracts derived from select whole-grain cereals. Food Res Int 51:518-525

8. Saura-Calixto F (2011) Dietary fiber as a carrier of dietary antioxidants: an essential physiological function. J Agric Food Chem 59:43-49
9. Manach C, Scalbert A, Morand C, Rémésy C, Jiménez L (2004) Polyphenols: food sources and bioavailability. Am J Clin Nutr 79:727-747

10. Saa DT, Di Silvestro R, Dinelli G, Gianotti A (2017) Effect of sourdough fermentation and baking process severity on dietary fibre and phenolic compounds of immature wheat flour bread. LWT-Food Sci Technol 83:26-32

11. Hidalgo A, Tumbas Šaponjac V, Ćetković G, Šeregelj V, Čanadanović-Brunet J, Chiosa D, Brandolini A (2019) Antioxidant properties and heat damage of water biscuits enriched with sprouted wheat and barley. LWT-Food Sci Technol 114:108423

12. Ti H, Zhang R, Zhang M, Li Q, Wei Z, Zhang Y, Ma Y (2014) Dynamic changes in the free and bound phenolic compounds and antioxidant activity of brown rice at different germination stages. Food Chem 161:337-344

13. Zielinski H, Kozlowska H, Lewczuk B (2001) Bioactive compounds in the cereal grains before and after hydrothermal processing. Innov Food Sci Emerg Technol 2:159-169

14. Abdel-Aal E-SM, Rabalski I (2013) Effect of baking on free and bound phenolic acids in wholegrain bakery products. J Cereal Sci 57:312-318

15. Hidalgo A, Yilmaz VA, Brandolini A (2016) Influence of water biscuit processing and kernel puffing on the phenolic acid content and the antioxidant activity of einkorn and bread wheat. J Food Sci Technol 53:541-550

16. Gallegos-Infante JA, Rocha-Guzman NE, Gonzalez-Laredo RF, Pulido-Alonso J (2010) Effect of processing on the antioxidant properties of extracts from Mexican barley (Hordeum vulgare) cultivar. Food Chem 119:903-906

17. Liyana-Pathirana CM, Shahidi F (2006) Importance of insolublebound phenolics to antioxidant properties of wheat. J Agric Food Chem 54:1256-1264

18. Fares C, Platani C, Baiano A, Menga V (2010) Effect of processing and cooking on phenolic acid profile and antioxidant capacity of durum wheat pasta enriched with debranning fractions of wheat. Food Chem 119:1023-1029

19. Venkatesan T, Choi YW, Kim YK (2019) Impact of different extraction solvents on phenolic content and antioxidant potential of Pinus densiflora bark extract. BioMed Res Int 12:3520675

20. Zhong L, Yuan Z, Rong L, Zhang Y, Xiong G, Liu Y, Li C (2019) An optimized method for extraction and characterization of phenolic compounds in Dendranthema indicum var. aromaticum flower. Sci Rep 9:7745

21. Abdel-Aal E-SM, Hucl P, Sosulski FW, Graf R, Gillott C, Pietrzak L (2001) Screening spring wheat for midge resistance in relation to ferulic acid content. J Agric Food Chem 49:3559-3566

22. Antognoni F, Mandrioli R, Potente G, Saa DLT, Gianotti A (2019) Changes in carotenoids, phenolic acids and antioxidant capacity in bread wheat doughs fermented with different lactic acid bacteria strains. Food Chem 292:211-216

23. Moore J, Hao Z, Zhou K, Luther M, Costa J, Yu L (2005) Carotenoid, tocopherol, phenolic acid, and antioxidant properties of Maryland-grown soft wheat. J Agric Food Chem 53:6649-6657

24. Hidalgo A, Brandolini A (2017) Nitrogen fertilisation effects on technological parameters and carotenoid, tocol and phenolic acid content of einkorn (Triticum monococcum L. subsp. monococcum): a two-year evaluation. J Cereal Sci 73:18-24

25. AACC (1995) AACC Official Method 44-15. In Approved Methods of the American Association of Cereal Chemists, St. Paul, MN, USA

26. Hidalgo A, Brandolini A (2011) Heat damage of water biscuits from einkorn, durum and bread wheat flours. Food Chem 128:471-478

27. Hoffman RE (2006) Standardization of chemical shifts of TMS and solvent signals in NMR solvents. Magn Reson Chem 44:606-616 
28. Yilmaz VA, Brandolini A, Hidalgo A (2015) Phenolic acids and antioxidant activity of wild, feral and domesticated wheats. J Cereal Sci 64:168-175

29. Re R, Pellegrini N, Proteggente A, Pannala A, Yang M, RiceEvans C (1999) Antioxidant activity applying an improved ABTS radical cation decolorization assay. Free Radical Biol Med 26:1231-1237

30. Benzie IFF, Strain JJ (1996) The ferric reducing ability of plasma (FRAP) as a measure of antioxidant power: the FRAP assay. Anal Biochem 239:70-76

31. Ait Ameur L, Mathieu O, Lalanne V, Trystram G, BirlouezAragon I (2007) Comparison of the effects of sucrose and hexose on furfural formation and browning in cookies baked at different temperatures. Food Chem 101:1407-1416

32. Don MJ, Shen CC, Syu WJ, Ding YH, Sun CM (2006) Cytotoxic and aromatic constituents from Salvia miltiorrhiza. Phytochem 67:497-503

33. Chheda JN, Dumesic JA (2007) An overview of dehydration, aldol-condensation and hydrogenation processes for production of liquid alkanes from biomass-derived carbohydrates. Catal Today 123:59-70

34. Kikhtyanin O, Kubička D, Čejka J (2015) Toward understanding of the role of Lewis acidity in aldol condensation of acetone and furfural using MOF and zeolite catalysts. Catal Today 243:158-162

35. Erba D, Hidalgo A, Bresciani J, Brandolini A (2011) Environmental and genotypic influences on trace element and mineral concentrations in whole meal flour of einkorn (Triticum monococcum L. subsp. monococcum). J Cereal Sci 54:250-254

36. Faba L, Díaz E, Ordóñez S (2012) Aqueous-phase furfuralacetone aldol condensation over basic mixed oxides. Appl Catal B113:201-211
37. Hidalgo A, Brandolini A (2010) Tocols stability during bread, water biscuit and pasta processing from wheat flours. J Cereal Sci 52:254-259

38. Hidalgo A, Brandolini A, Pompei C (2010) Carotenoids evolution during pasta, bread and water biscuit preparation from wheat flours. Food Chem 121:746-751

39. Lindenmeier M, Hofmann T (2004) Influence of baking conditions and precursor supplementation on the amounts of the antioxidant pronyl-L-lysine in bakery products. J Agric Food Chem 52:350-354

40. Morales FJ, Martin S, Açar OC, Arribas-Lorenzo G, Gökmen V (2009) Antioxidant activity of cookies and its relationship with heat-processing contaminants: a risk/benefit approach. Eur Food Res Technol 228:345-354

41. Haase NU, Grothe K-H, Matthäus B, Vosmann K, Lindhauer MG (2012) Acrylamide formation and antioxidant level in biscuits related to recipe and baking. Food Addit Contam Part A 29:1230-1238

42. Virág D, Kiss A, Forgó P, Csutorás C, Molnár S (2013) Study on Maillard-reaction driven transformations and increase of antioxidant activity in lysine fortified biscuits. Microchem J 107:172-177

Publisher's Note Springer Nature remains neutral with regard to jurisdictional claims in published maps and institutional affiliations. 